\title{
Emergency Lighting System
}

$\mathrm{L}$ andmark Plastic Corporation, Akron, Ohio is a manufacturer of plastic trays, packs, pots and other specialty horticultural products for customers in the U.S. and abroad. Landmark's Maintenance Department reports that technology in a NASA Tech Briefs (see page 129) article provided an important costreducing, safety-enhancing benefit through improvement of the company's emergency lighting system (ELS).

Landmark's main factory lighting consists of banks of 400 watt 277 VAC mercury vapor bulbs (right). When a power outage occurs, two ELS sets take over. One is the standard low watt battery system; the other is composed of $120 \mathrm{VAC}$ incandescent lamps that come on automatically when one leg of the mercury vapor main factory lighting is lost.

Landmark had a problem with this system. When a power outage occurred. it took seven to 12 minutes for the primary mercury lamps to cool down before they would relight. In addition, it took two to seven minutes for the 120 VAC 200 watt ELS incandescent lamps to activate. That meant that there was a period of as much as seven minutes before production could resume, a period during which the light supplied by the low watt battery system was so dim that lights mounted on forklifts were used to illuminate the production area.

Steve Keller of the Maintenance Department was asked to design and build an ELS panel that would allow the $120 \mathrm{VAC}$ incandescent lights to come on instantaneously after a power outage, permitting immediate resumption of production. Keller is pictured below working on his design.

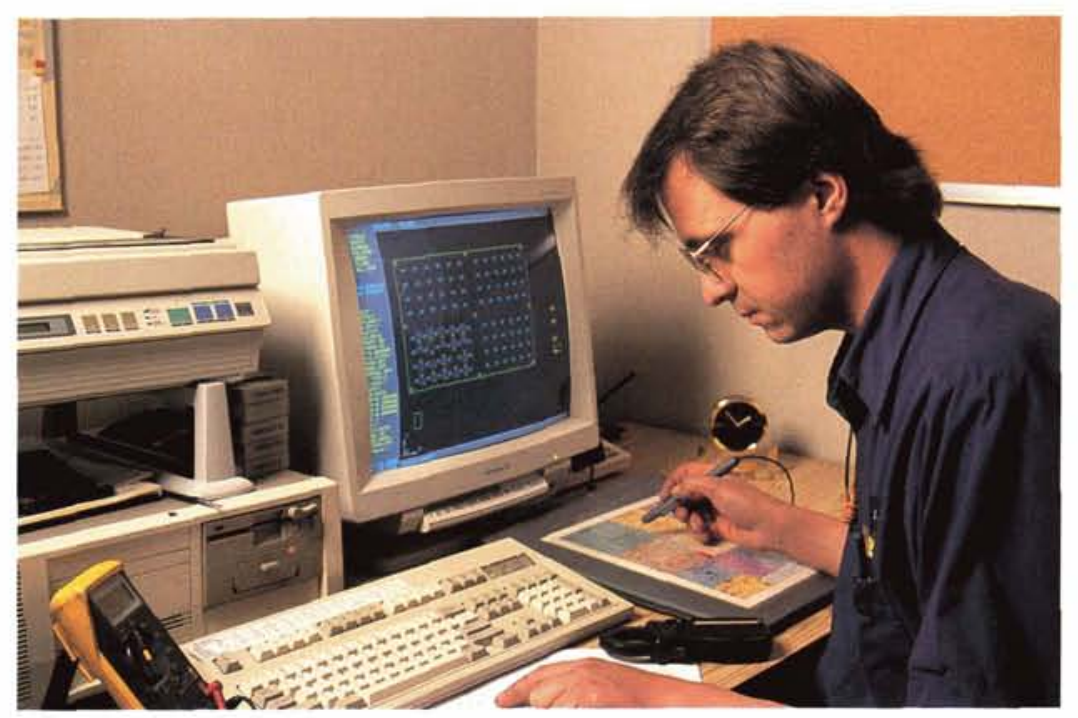

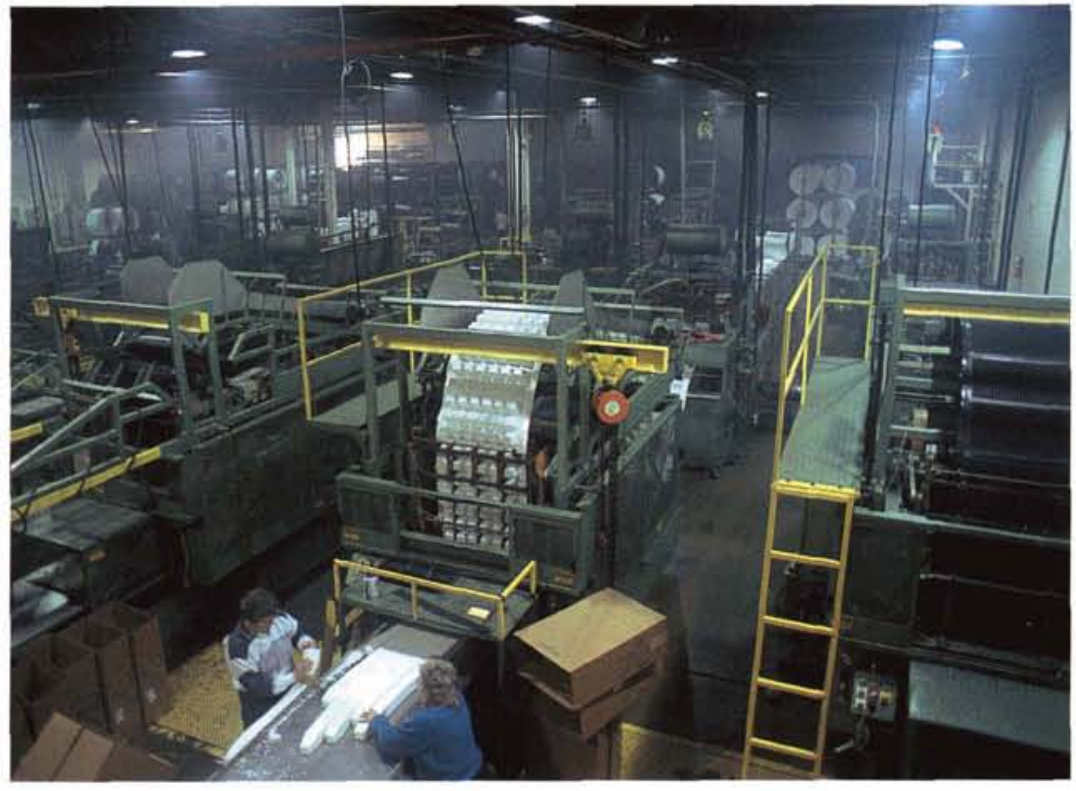

Keller's solution was a system wherein the $120 \mathrm{VAC}$ bulbs are activated by any loss of voltage in the $277 \mathrm{VAC}$ main lamp circuit. coupled with photosensing devices used to keep the ELS on until the 277 VAC primary mercury lamps reach full brightness. Keller credits NASA Tech Briefs with an assist: he learned about the capabilities of photosensing devices from a Tech Briefs article on photodetector technology developed at Marshall Space Flight Center.

The new system is in place and the Landmark plant is safer because there is no longer a period of dim light and more productive because production is resumed more quickly after a power outage, and in manufacturing operations time is literally money. 